Aleksander Michalski, Magdalena Kwiatek, Alicja Mełgieś Justyna Joniec-Wiechetek and Krzysztof Lasocki

\title{
2. PERSONAL PROTECTIVE MEASURES
}

\subsection{Introduction}

Collecting samples in an area potentially contaminated with CBRN agents is a challenging task. There are not only the hazardous materials to consider, but also other threats related to hostile activity or environmental hazards, such as IEDs or wild animals. These problems can also pose a significant risk to first responders and CBRN survey teams. Physically securing areas with armoured guards and antecedent activity of EOD patrol may reduce risk and allow personnel to focus on sampling mission. Nevertheless, there are unlimited scenarios for sampling which may happen during $\mathrm{CBRN}$ incident or terroristic attack, the common sense and general procedures constitute the base for successful missions. Depending on organizational approach or specific scenario, CBRN survey and sampling may rely on general NBC teams or specialized teams (chemical, radiological and biological). The biological agents with their intrinsic pathogenic and/or toxic properties, which include incubation period, communicability or unspecific symptoms and delayed diagnosis, are one of the greatest potential threats. Thus appropriate methods, practices and countermeasures have to be applied to reduce biological risk for first responders or sampling personnel. These include personal protective equipment, medical pre- and post-exposure prophylaxis as well as antiseptic and aseptic procedures during mission. Moreover training in special practices related with decontamination of PPE and equipment which leaving the zone, including enhanced general hygiene or even food consumption can't be neglected.

All measures which have positive influence on personal safety of potentially exposed duty officers, need to be undertaken. Considering specific nature of biological warfare agents they also protect non-exposed personnel, as well as their relatives and general public health. This chapter will focus on these aspects.

\subsection{Biorisk assessment}

Biological risk assessment and management is prerequisite action for successful biological sampling mission preparation. Even though there are unlimited numbers of CBRN scenarios, there are also defined lists of pathogens which can be used as 
biological warfare agents, which have been discussed in previous chapters. Considering their properties as well as disease characteristic and availability of prophylaxis and treatment medications, the general or specific biological countermeasures may be planned and applied. Following aspects of biological warfare agents need to be considered during the biorisk assessment process:

- Survivability/stability in environment - bacteria are substantially more stable in the environment (bacterial spores can survive for many years in soils), while viruses are less stable, but non-enveloped viruses are more resistant than enveloped ones;

- Sensitivity to disinfection substances - the vegetative forms of bacteria and enveloped viruses are sensitive to majority of disinfectants. However spores are resistant to many disinfectants. Additionally, non-enveloped viruses, mycobacteria and fungi may be resistant to some types of chemicals;

- Probable dissemination method - the most likely pathway for the spread of many pathogens is an aerosol form, however there are some agents which can be used to contaminate water or food chain, or with using vectors;

- Infectious dose - the number of microorganisms required for development of an infection. This also depends on pathogen species or port of entry. For example, approximately one virus particle or 5-10 cells of F. tularensis (respiratory route) are sufficient for infection, whereas in case of $B$. anthracis from 8,000 to 50,000 endospores are required. In many cases the infectious dose is unknown or only rough estimated.

The other significant input for biorisk assessment is characteristic of diseases and available adequate prophylaxis and treatment medicines. These are:

- Incubation period - for different microorganisms is varied. It can last for several hours (Escherichia coli), a few days (Influenza Virus, Yersinia pestis, Dengue virus), and even a few months. This information may be valuable to predict quarantine and observation time;

- Mortality (number of fatal casualties related to number of cases) and prevalence. These factors determine a disease severity and directly allow to assess hazard related with agent, and potential consequences of exposure. It is also important to distinguish these factors among treated patients and non-treated patients as well as vaccinated and not vaccinated ones;

- Communicability of disease - there are direct and indirect ways of spreading of the infection. The direct way can be divided into: direct contact with sick person (e.g. contact with body fluids (Ebola virus, Marburg virus), droplets spreading during coughing and sneezing (Influenza viruses), sexual contact (Zika virus), vertical infection, from mother to child (through the placenta, during labour or breastfeeding). While the indirect contact includes: skin contact with contaminated material (Bacillus anthracis), faecal-oral route, consumption of contaminated water and food (Escherichia coli, Vibrio cholerae), aerosol route (pulmonary plague and tuberculosis) and infection by vectors e.g. direct contact with sick animal (e.g. bites or stings by infected animals (Hantaviruses) or insect 
bites (West Nile virus, Dengue virus, TBE) or contact with waste containing microorganisms particles (Hantaviruses);

- Availability of vaccines and/or antibiotics - the presence of preventive measures and effective therapy to a particular pathogen significantly minimizes related biorisk. Basically, antimicrobial therapy is widely available, but when it comes to viruses, the specific treatment opportunities are very limited, rather supportive treatment is available. Moreover there might be some discrepancies of treatment measures in various countries depending on condition of medical service and wealth.

This information above will contribute to appropriate selection of disinfection substances, respiratory and personnel protection measures, needed vaccination or chemoprophylaxis measures. The characteristics of resulted disease will influence on medical procedures in case of exposed personnel or rescued casualties. The most challenging situation will occur in case of unknown agent. The worst case scenario has to be always foreseen in biorisk management. However, it might be presumed that in real situations (such as Anthrax letter incidents from year 2001), additional information about anticipated biological agents may be available. These may allow for more narrowed and specific biorisk assessment and management.

\subsection{Medical measures}

Medical prophylaxis and treatment medicines are very effective countermeasures in the long-lasting war of humanity against infectious diseases. Antibiotics and vaccines can also be very useful to protect personnel against biological warfare agents (Table 1). Thus, knowledge about available prophylaxis and medical measures is an essential point in mission preparation. Basing on results of biorisk assessment concerning particular agents and activities, vulnerable personnel has to be advised or obligated to undertake necessary medical measures to minimize the risk of infection. A special stockpile of these pharmaceuticals need to be prepared and stored in advance of any event. There might by requirements of prophylactic vaccination for duty officers in case of potential occupational exposure. There are for example legal requirements of vaccination in Poland for national defence and interior affairs ministries units. Vaccines are the main and the most effective medical prophylactic measures from the medical point of view. However, biological warfare agents and related diseases currently are not the top listed threats for public health. Thus, vaccines for them may be not easily available or there exist no vaccine on the market for some biological agents. On the other hand, widely available antibiotics, may be used for post-exposure prophylaxis or treatment of bacterial diseases. For viral biological warfare agents, special antiviral drugs may be applied, however often their efficacy are not fully tested or confirmed. Moreover, for some biological warfare agents specific immune antibodies (as well as antitoxins and antisera) can be applied against selected viruses, bacteria or toxins. 
In case of directed or suspected exposure on biological warfare agent, especially in case of unvaccinated personnel - there is a need to implement special post-exposure prophylaxis procedures. The detailed action is heavily related to the characteristic of agent and disease (communicability, mode of transmission, infectivity, course of disease and availability of pharmaceuticals).

Table 1. List of diseases caused by potential biological warfare agents, with available vaccines and drugs

\begin{tabular}{|c|c|c|c|}
\hline Disease & $\begin{array}{c}\text { Causative } \\
\text { agent }\end{array}$ & Vaccine & Drugs \\
\hline Anthrax & $\begin{array}{l}\text { Bacillus an- } \\
\text { thracis }\end{array}$ & $\begin{array}{l}\text { available } \\
\text { (purified } \\
\text { antigen) }\end{array}$ & $\begin{array}{l}\text { penicillin (except for inhalation anthrax } \\
\text { in which the mortality remains high), } \\
\text { ciprofloxacin, doxycycline, tetracyclines, } \\
\text { erythromycin, chloramphenicol }\end{array}$ \\
\hline $\begin{array}{l}\text { Pneumonic } \\
\text { plaque }\end{array}$ & Yersinia pestis & available & $\begin{array}{l}\text { streptomycin, tetracycline, chloram- } \\
\text { phenicol (for cases of plague meningitis), } \\
\text { kanamycin, ROM therapy }\end{array}$ \\
\hline Tularemia & $\begin{array}{l}\text { Francisella } \\
\text { tularensis }\end{array}$ & $\begin{array}{l}\text { during } \\
\text { the tests }\end{array}$ & $\begin{array}{l}\text { streptomycin, ciprofloxacine, gentamycin, } \\
\text { tobramycin, kanamycin, tetracyclines, } \\
\text { chloramphenicol, aminoglycosides }\end{array}$ \\
\hline Brucellosis & Brucella suis & $\begin{array}{l}\text { not avail- } \\
\text { able for } \\
\text { humans }\end{array}$ & $\begin{array}{l}\text { tetracyclines, doxycycline with rifampicin, } \\
\text { streptomycin, trimethoprim/ sulfame- } \\
\text { thoxazole (TMP/SMX) }\end{array}$ \\
\hline Q-Fever & $\begin{array}{l}\text { Coxiella bur- } \\
\text { netii }\end{array}$ & available & $\begin{array}{l}\text { cotrimoxazole, rifampin, doxycycline, } \\
\text { minocycline, tetracycline, clarithromycin, } \\
\text { sparfloxacin, } \\
\text { quinolones }\end{array}$ \\
\hline Glanders & $\begin{array}{l}\text { Burkholde- } \\
\text { ria mallei, } \\
\text { Burkholderia } \\
\text { pseudomallei }\end{array}$ & $\begin{array}{l}\text { not avail- } \\
\text { able }\end{array}$ & $\begin{array}{l}\text { trimethoprim/sulfamethoxazole (TMP/ } \\
\text { SMX), ceftazidime, imipenem, doxycy- } \\
\text { cline, minocycline, ciprofloxacin, gentami- } \\
\text { cin, ciprofloxacinsulphas, chlorampheni- } \\
\text { col, tetracycline }\end{array}$ \\
\hline Smallpox & Variola virus & available & $\begin{array}{l}\text { no specific treatment is available but cido- } \\
\text { fovir may be effective }\end{array}$ \\
\hline $\begin{array}{l}\text { Venezuelan } \\
\text { Equine } \\
\text { Encephalitis }\end{array}$ & $\begin{array}{l}\text { Venezuelan } \\
\text { Equine En- } \\
\text { cephalitis virus }\end{array}$ & available & no specific treatment is available \\
\hline
\end{tabular}




\begin{tabular}{|c|c|c|c|}
\hline Disease & $\begin{array}{c}\text { Causative } \\
\text { agent }\end{array}$ & Vaccine & Drugs \\
\hline $\begin{array}{l}\text { Marburg } \\
\text { Fever }\end{array}$ & $\begin{array}{l}\text { Marburg Fever } \\
\text { virus }\end{array}$ & $\begin{array}{l}\text { not avail- } \\
\text { able }\end{array}$ & no specific treatment is available \\
\hline Botulism & $\begin{array}{l}\text { toxin of } \\
\text { Clostridium } \\
\text { botulinum }\end{array}$ & $\begin{array}{l}\text { not avail- } \\
\text { able }\end{array}$ & antitoxin \\
\hline $\begin{array}{l}\text { Ricin-intox- } \\
\text { ication }\end{array}$ & Ricin & available & no specific treatment is available \\
\hline $\begin{array}{l}\text { SEB-intoxi- } \\
\text { cation }\end{array}$ & $\begin{array}{l}\text { Staphylococcal } \\
\text { enterotoxin B }\end{array}$ & $\begin{array}{l}\text { not avail- } \\
\text { able }\end{array}$ & no specific treatment is available \\
\hline
\end{tabular}

Post-exposure measures may include: observation of casualty's health status, quarantine, application of antibiotics or antivirals or antibodies (antitoxin or antisera) as well as vaccination or revaccination (booster-doses) or combining these measures. Once symptoms of diseases developed, patients may be treated in isolation wards to prevent spread of disease in case of highly contagious and dangerous disease.

\subsection{General protective equipment}

Personal protective equipment (PPE) consists of specialized clothing or equipment used to prevent contact of personnel with hazardous CBRN materials. The PPE provides physical barriers that protect the potential entry ports for biological agents (hands, skin, eyes, nose, respiratory system and mouth) against contact with infectious agents, and potential infection or intoxication. This includes garments (suit, gowns, uniform), respiratory protection equipment, gloves, safety glasses, helmets, hoods, face shields, rubber boots and others. The PPE must be worn at all times during work with dangerous substances or sampling mission. Final selection of PPE, as a result of the risk assessment, has to base on mission-work environment description, analysis of potential hazardous agent, type of activity as well as individual capacities to fulfil the task in PPE. It is mandatory in European Union for employer to select and provide PPE, train personnel how to use it, as well as clean/decontaminate or dispose it. Legal requirements for PPE production and testing, including CE marking of PPE fall under European directive, which will be suppressed in near future with the directly applicable European regulation.

The main type of garment PPE for biological sampling mission are disposable or reusable coveralls (suits), which are more preferably used than other type of garment PPE, due to comfort of movement and readiness for decontamination 
procedure. There are currently three categories of work-protective garment. Categories II and III are considered PPE, but for CBRN sampling missions the garment must belong to Category III (specialized cloths), which is applied to the life and health risks situations.

Current European standards for PPE, which can be used in biological sampling, relate to general demands for protective clothing but there are more specific document which cover biological safety. Since unknown event areas can also be burdened with other threats, other hazards like chemicals or radiation mustn't be neglected. Moreover decontamination procedure very often envisages disinfecting shower with harmful chemical substances. Various types of protective garments can be applied for situations, where chemical, biological, radiological or nuclear warfare hazards may be present (Table 2).

The European Standards specify the tests methods for materials intended to be used in the manufacturing of each type of protective clothing. General division into six types (depending on form of the threat: gas, particles liquid, vapours), relates to chemical safety but each type may be tested against biological agents according to EN 14126 which specify requirements and tests methods for protective clothing against infective agents (letter ' $\mathrm{B}$ ' in suit code name).

Additional elements of protective suits may also be necessary to fully equip the personnel. These are for example gloves, which have to be both chemically and biologically resistant. On the other hand, they have to be thin enough to allow for precise work. Appropriate gloves must be worn for all procedures that may involve direct or accidental contact with blood, body fluids and other potentially infectious materials or infected animals. A special attention has to be paid for potential allergenic properties of material which has direct contact with skin. Many CBRN sampling teams work in double gloves regime (gloves are changed after changing location of sampling or collection of another sample), it is a reasonable approach compared to alternative option basing on frequent disinfection of gloved hand. Depending on suit type and presumed activity, many other items can also be useful: aprons, sleeves, rubber boots, safety glasses, face shields (visors) or other protective devices which must be worn when it is necessary to protect eyes and face from splashes or impacting objects.

Depending on the type and form of biological agent, exposure levels, type of work and risk of infection, consideration should be given to selection of the most adequate type of category III garment. General rule is that personnel which enters the unknown hot zone have the most advanced PPE (for example overpressure suits) whereas personnel engaged in warm zone (e.g. buddy decontamination, undoing or sample processing) wear lighter suits (e.g. with negative pressure respirators). 
Table 2. Personal protective equipment - category III cloths types

\begin{tabular}{|c|c|c|c|}
\hline Type & Pictogram & & European standards \\
\hline Type 1a & & $\begin{array}{l}\text { Full body protection against } \\
\text { gaseous and airborne agents } \\
\text { (respiratory device inside the } \\
\text { suit). }\end{array}$ & $\begin{array}{l}\text { EN } 943-1 \text { and tested by EN } \\
464: 1994 \text { if used by the } \\
\text { emergency team, also EN } \\
943-2 \text { (code name: } 1 \text { a-ET) }\end{array}$ \\
\hline Type $1 b$ & & $\begin{array}{l}\text { Full body protection against } \\
\text { gaseous and airborne agents. } \\
\text { (respiratory device outside the } \\
\text { suit). }\end{array}$ & $\begin{array}{l}\text { EN } 943-1 \text { and tested by EN } \\
464: 1994 \text { if used by the } \\
\text { emergency team, also EN } \\
943-2 \text { (code name: } 1 \text { b-ET) }\end{array}$ \\
\hline Type 1c & & $\begin{array}{l}\text { Full body protection against } \\
\text { gaseous and airborne agents. } \\
\text { (breathing air provided by hose } \\
\text { from outer stationary source). }\end{array}$ & $\begin{array}{l}\text { EN } 943-1 \text { and tested by EN } \\
464: 1994\end{array}$ \\
\hline Type 2 & & $\begin{array}{l}\text { Full body protection against } \\
\text { gaseous and airborne agents. } \\
\text { (by positive pressure inside the } \\
\text { suit). }\end{array}$ & $\begin{array}{l}\text { EN 943-1, not tested against } \\
\text { EN 464:1994 }\end{array}$ \\
\hline Type 3 & & Protect against jets of liquid. & $\begin{array}{l}\text { EN 17491-3 } \\
\text { EN 14605+A1:2009 }\end{array}$ \\
\hline Type 4 & & Protect against sprayed liquid. & $\begin{array}{l}\text { EN 17491-4 } \\
\text { EN 14605+A1:2009 }\end{array}$ \\
\hline Type 5 & & $\begin{array}{l}\text { Protect against dust and airbor- } \\
\text { ne solid particles. }\end{array}$ & EN 13982-1:2004+A12010 \\
\hline Type 6 & & $\begin{array}{l}\text { Limited protection against } \\
\text { splashing of liquid. }\end{array}$ & EN 13034:2005+A1:2009 \\
\hline $\begin{array}{l}\text { Type } \\
1-6-\mathrm{B}\end{array}$ & & $\begin{array}{l}\text { Protect against biological } \\
\text { agents. }\end{array}$ & EN 14126:2003 \\
\hline
\end{tabular}

The other consideration related with thermal comfort of the personnel has to be included in planning. The majority of current biological suits are made from multilayer fabrics, which intend to provide both adequate resistance, barrier and improved vapour-permeability for comfortable usage. These fabrics 
or synthetic materials are sophisticated laminates - multilayer materials made from polyurethane, polypropylene, polyethylene, polyester, cellulose, porous materials and breathable membranes. More resistant and thick fabric may result in decreased permeability and consequently decreased comfort of work in suit in hot or humid environments. This circumstance need to be overcome by shortening of the mission or application of cooling vests which allow to decrease temperature under the suit. The cooling effect may be obtained by thermoelectric effect (it needs electricity from portable battery), a phase change effect or ice packs. On the other hand in colder climate, the appropriate warm underwear have to be used to keep warmness under the suits.

Below four examples of the disposable Category III protective suits, which can be used in various type of missions and activities, are presented. The first suit (PROTEC Plus) is rather light and may be used in presence of limited threats or warm zone activities (Fig. 1). It is made from breathable layer/microporous film (PE/PP). This suit is type $4 \mathrm{~B}, 5 \mathrm{~B}, 6$ (protection against dust, particles, fibres and diffused substances) with protection against radioactive contaminating particles and biological hazardous substances. It is intended for work with lighter activities involving work with liquid and solid moderately hazardous substances (non-pressurized). It may be combined with any respiratory protection measure and other add-ons.

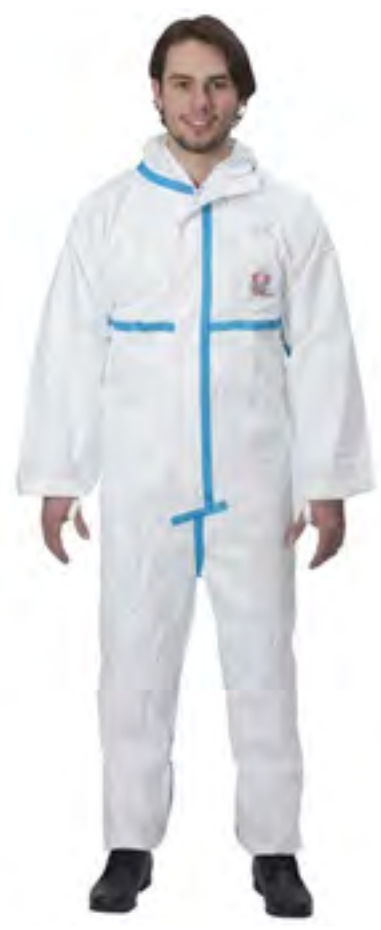

Figure 1. Example of a light Category III suit (type 4B, 5B, 6) 
The second example suit (ProChem II C/F - category III, type 3B, 4, 5 and 6 - Fig. 2) may be easily and tightly combined with negative pressure respirator (full-face facepiece) via butyl face shield seals as well as gloves (various types: butyl, nitrile, chloroprene) and rubber boots (or shoe covers with nonslip and antistatic sole). Entrance is from the back (a safer 'solid front' approach) and secured with two tabs closed with double-sided adhesive tape. It is much heavier (material: Tychem $\mathrm{F}$ or $\mathrm{C}$ ) compared to previous one (version $\mathrm{C}$ is lighter, though). It is intended for more intensive works including entering hot zone and direct sampling. It provides protection against inorganic and organic chemicals (only version $\mathrm{F}$ ) in high concentration, dangerous biological hazards and contamination with particles, fibres and dust, radiation and protection against toxic warfare agents. It is resistant against even intensive personnel decontamination shower applied before leaving the hot zone.

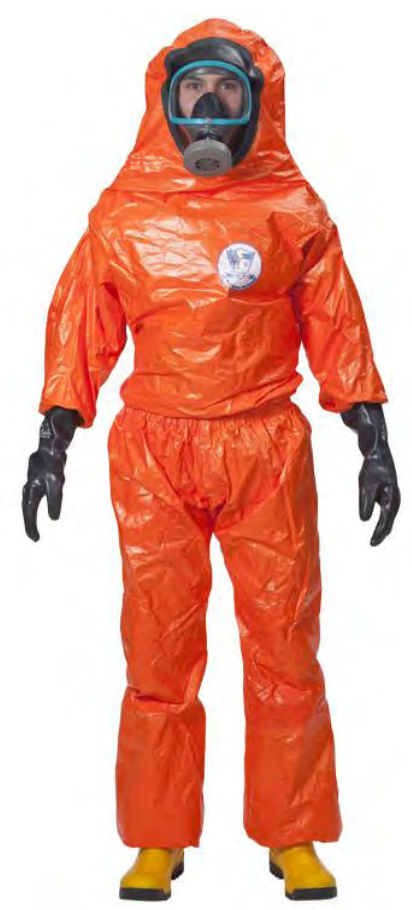

Figure 2. Example of a heavier Category III suit (type 3B, 4, 5, 6)

The following example (ProChem III F or C - category III type 3 and 5; Fig. 3 ) is interesting due to combining it with powered air purifying respirator (PAPR) as a respiratory protection measure. It is made from the same material (Tychem $\mathrm{F}$ or $\mathrm{C}$ ) and provides similar properties capacities as previous ones. It can also be supplemented with similar additional add-ons. The main 
advantage of this type is application of the battery operated filtering device which eliminates the use of full-face facepiece respirator. Hence, it allows for prolonged (few hours) mission in more comfortable conditions - breathing is not restricted by negative pressure respirator. Impressive panoramic visor and size of suit's head part will improve observation field and it may help users who has problem with claustrophobia. Placing the PAPR device under the coverall (only the filtering units are outside) prevents it from being contaminated. The air from outside is filtered (at least P3 filters which may be combined filter against chemical/radiological agent) and clean air is blown over the head. This gives additional advantage for thermal / humidity comfort. Even though it was not tested against requirements of type 2 garment, it provides additional protection due to relative overpressure inside the garment, which prevents penetration of hazardous gases and particles. There are also similar types of suits, but combined with SCBA (self-contained breathing apparatus) instead of PAPR, which have their own advantages and disadvantages.

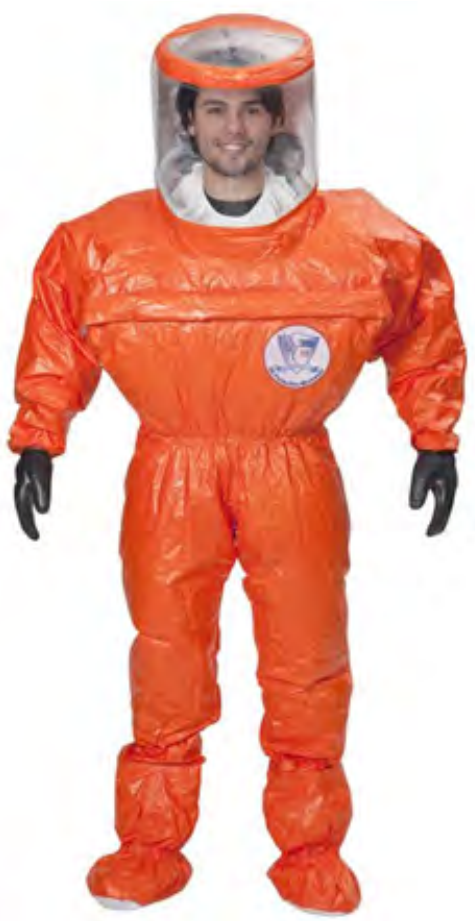

Figure 3. Example of a heavier Category III suit (type 3B, 4, 5, 6) with PAPR

The last example (ProChem VI TK - category III, type 1a - Fig. 4) is the most advanced solution, providing maximum gaseous barrier for CBRN 
hazards, even in higher concentration and under the pressure. The suit is made from heavy material Tychem ${ }^{\circ} \mathrm{TK}$ (triple dense as previous ones). It is equipped with breathing apparatus with compressed air and full-face facepiece as respiratory protection measure, which provide additional overpressure inside the suit. As a whole the suit and breathing apparatus provide protection against highly concentrated substances as well as in presence of toxic industrial materials, for which regular military or civilian chemical filter based negative respirators may be not sufficient. As the type $1 \mathrm{a}$, the self-contained breathing apparatus is under the suit, which protects this expensive device against potential contamination. Panoramic visor of facepiece respirator and suit provide adequate observation field. It may be supplemented with sealed 'socks' or air-tight sealed rubber boots. The suit is combined with double glove work system, thinner gloves inside and thicker ones outside. It is tested additionally against standard EN 943-2 to meet special requirements for emergency rescue teams equipment.

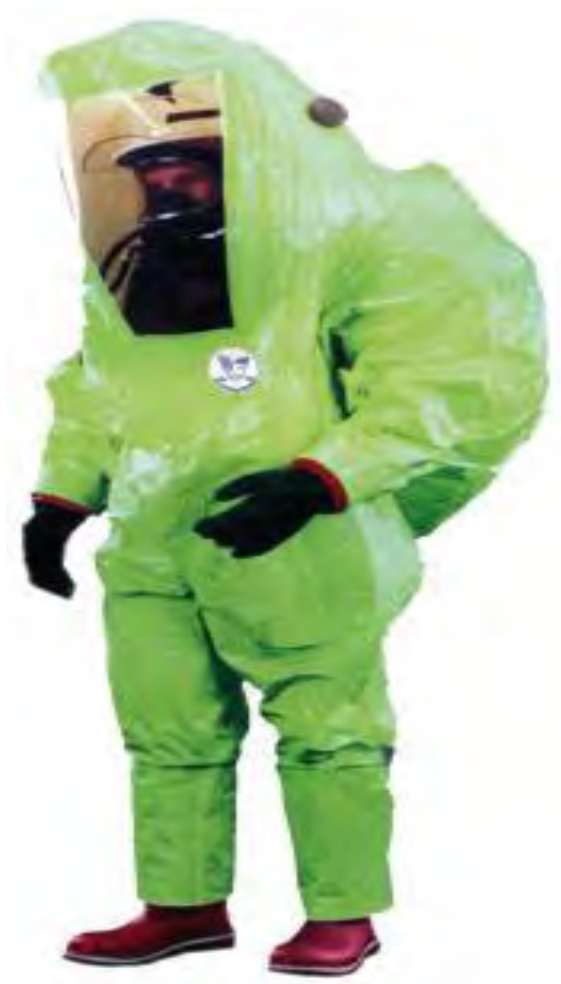

Figure 4. Example of a heavy Category III (type 1a -ET), air-tight, SCBA-equipped suit for emergency teams 


\subsection{Respiratory safety}

The main probable dissemination route for majority of biological warfare agents is aerosol. The primary threat: aerosolized bacteria, viruses or toxins are odourless and rather invisible. Once settled down, they contaminate affected area and equipment. The resulting biological fallout is source re-aerosolization and secondary threat. Thus protection respiratory tract is the indispensable part of biological PPE. There are two approaches for respiratory protection isolation and filtration. The first method bases on supply of clean air (or oxygen) from an independent source. There are two types: stationary (air is supplied by air-hose) and autonomous (such as self-contained breathing apparatus SCBA). The second one, which bases on bottle of compressed air is preferably used in CBRN protection and by first responders. It provides the superior safety, which also includes other hazards (chemical gases, vapours, decreased level of oxygen) over filtration based methods. Moreover, they are positive pressure respirators (the pressure of clean air inside the facepiece is greater than outside) which is another safety advantage. However limited air amount in an autonomous highpressure tank allows for missions which take less that one hour for the open circuit systems or four hours for the closed circuit system. The closed circuit system is more sophisticated and it is based on recirculation and recycling of exhaled gas. Thus the closed circuit SCBAs are much more expensive and complex in terms of routine maintenance, hence they are less widely used in CBRN protection.

The filtration based approach is more widely implemented in CBRN protection. It is simpler in use, cheaper in production and maintenance as well as suitable for long term storage. It consists of reusable facepiece (full-face facepiece or half-mask) and filtration unit (sometimes also adsorbing) or disposable filtering facepiece (FFP), where the whole facepiece functions as filter. The majority of filtration based masks are negative respirators (the pressure of clean air inside the facepiece during the inhalation is lower than outside). Full-face facepieces (e.g. regular military mask) are more favourable than half-masks, because they also offer face and eyes protection, however observation field and comfort of work is limited. Thus shape of facepiece has to be precisely fitted to the face, to reduce the risk of inhalation of unfiltered air $(\max .0 .05 \%)$. The singleuse filtering facepieces (half masks) are being more popular nowadays. They are cheaper, lightweight and disposable, thus more comfortable (they do not need to be decontaminated after action). The disadvantages of this solution is related with their shape (half masks, which generate higher inward leakage) and difficulties to obtain adequate face seal.

The filtration based respiratory protection PPE may be enhanced with airflow supported by e.g. battery operated electric blower. This enhancement 
leads to improved safety with applied mask, half mask as facepiece (power assisted filtering devices) and an implementation of positive pressured but loosely fitted facepieces like hoods or helmets (powered filtering devices). For example powered air purifying respirator (PAPR) connected with hood or overall suit (Fig. 4), offers better thermal comfort, observation field, longer work and comparable safety to other options (SCBA or negative pressure protective mask). This approach is being more popular in case of the absence of co-occurring radiological or heavy chemical contaminations.

Table 3. Filter classes under standards EN 143 and EN 149

\begin{tabular}{|c|c|c|c|c|c|c|}
\hline $\begin{array}{c}\text { Filter } \\
\text { class EN } \\
\text { 143:2000 }\end{array}$ & $\begin{array}{l}\text { Min. } \\
\text { efficacy } \\
(\%)\end{array}$ & Other marks: & $\begin{array}{c}\text { FFP } \\
\text { class EN } \\
149: 2001\end{array}$ & $\begin{array}{c}\text { Minimum } \\
\text { efficacy } \\
(\%) \\
\end{array}$ & $\begin{array}{c}\text { Inward } \\
\text { leakage } \\
(\%)\end{array}$ & \begin{tabular}{|c|} 
Occupational \\
Exposure \\
Limit
\end{tabular} \\
\hline P1 & 80 & \multirow{3}{*}{$\begin{array}{c}\text { NR - disposable } \\
\text { R - reusable } \\
\text { Colour: white }\end{array}$} & & 80 & $<22$ & $4 \times \mathrm{OEL}$ \\
\hline $\mathrm{P} 2$ & 94 & & FFP2 & 94 & $<8$ & 9x OEL \\
\hline P3 & 99.5 & & FFP3 & 99.5 & $<2$ & $20 \times \mathrm{OEL}$ \\
\hline
\end{tabular}

Filtration efficacy of filtration units or filtration facepiece against solid and liquid aerosols falls into three classes in European Union (Table 3). Similar classifications exist in, for example, the USA (Table 4).

Table 4. Filtration efficacy based on 42 CFR Part 84 (US)

\begin{tabular}{|c|c|c|}
\hline $\begin{array}{l}\text { Filter } \\
\text { class }\end{array}$ & $\begin{array}{c}\text { Minimum } \\
\text { efficacy }(\%)\end{array}$ & Type of test \\
\hline 95 & 95 & \multirow{3}{*}{$\begin{array}{l}\mathrm{N} \text { - non-oil aerosols (e.g. N95, N99, N100) } \\
\mathrm{R} \text { - include oil aerosols with restrictions (e.g. R95, R99, R100) } \\
\mathrm{P} \text { - include oils aerosols (e.g. P95, P99, P100) }\end{array}$} \\
\hline 99 & 99 & \\
\hline 100 & 99.97 & \\
\hline
\end{tabular}

Filtering units may be combined with adsorbing materials and also provide protection against chemical agents. The respiratory protection equipment may be sensitive to inappropriate storage condition (temperature, humidity). Filter units are normally packed in hermetic bags, once they were opened, there may be some restrictions to reuse them. Respiratory protection PPE has maximum time of storage, which is marked on filtering unit or facepieces. It must never be used after the expiration date. For some power assisted or powered devices, a special attention has to be paid on batteries (in blower part) - they may need periodical recharging to sustain their lifetime and efficacy. 
The prolonged usage of respiratory protection equipment may be related with serious sensorial stress (limited hearing, smell and observation field). That is why decision about enrolment of personnel to use the respiratory protection equipment and its careful selection has to include: type of activity, individual capacities and environmental conditions. Moreover individual capacities are related with age, sex, hair and shape of face (e.g. beard), psychological and neurological conditions (e.g. claustrophobia), health status (pregnancy, respiratory insufficiencies or chronic conditions). Since respiratory protection equipment usage need some fluency - the enrolled personnel has to undergo initial and refreshing trainings to sustain practical skills and readiness to unexpected events during the mission.

\subsection{Personnel decontamination}

Leaving the hot zone comprises significant risk related with transferring biological warfare agent out of contaminated zone. Thus all necessary actions should be undertaken to prevent uncontrolled release of agents into the 'clean' environment and to protect staff against potential infection or contamination by dangerous substances. Thus a comprehensive and credible decontamination is indispensable both after finishing work with dangerous substances and after work in the field where unidentified agents would have occurred. A whole process of decontamination should concern both equipment (including reusable elements and devices) and clothes (including boots, garment, gloves) of every person who may have been exposed to potential hazardous substances or agents.

Wastes remaining after sampling mission (such as used disposable garments, plasticware), and wastewater after decon procedure are hazardous wastes due to potential presence of harmful CBRN warfare agents or chemical disinfecting agents. Hence they are also subject to appropriate utilization processes like other hazardous wastes. The hazardous wastes management are regulated by series of general policies and specific regulations. Due to chemical and biological threats the waste from biological sampling mission may be included in group H9 Infectious, H4 Irritant, H5 Harmful, H6 Toxic. There are different methods and schemas which may be applied for infectious wastes utilization: autoclaving, chemical or microwave treatment, alkaline hydrolysis. Despite final burning in incinerator is not the cheapest method, it is the most effective one for reduction of waste volume and hazard.

On-site decontamination process often is undertaken in specially assigned warm (yellow) zone between hot zone (red) zone and cold (green) one. It can relate to the first responders' equipment, as well as to potentially exposed casualties (mass-decontamination corridors). The simplest but also the most effective approach is physical removal of dangerous agent by water solutions under field showers. Warmer water and some additives of detergents increase comfort and efficacy of process. This method is also environmentally friendly and has not 
harmful side-effects to human health. On the other hand the increased risk may impose application of additional inactivating chemical agents. The combination of both methods (physical removal and chemicals) is more effective. There are several biocidal chemicals which can be used in solutions for decontamination procedures in the field condition. These are for example solutions based on: chlorhexidine, active chlorine (e.g. sodium hypochlorite), hydrogen peroxide, potassium monoperoxysulfate, peracetic acid or quaternary ammonium compounds (QAC). There are also several factors which have to be taken into account in planning effective decontamination and selection of appropriate biocide chemicals. The first one is its spectrum of activity, some disinfectants may not be equally active against all type of biological agents. There are some discrepancies especially in activity against bacterial spores, un-enveloped viruses, mycobacteria and fungi. Sometimes activity of disinfectant may be impaired by presence of organic substances. Hence the type and concentration of disinfectant or deactivator should be adjusted to the type of contaminant. Recently, solutions based on potassium monoperoxysulfate (and other ingredients) have been considered as disinfectants with the most broad spectrum. The side effects of disinfectants to human health (e.g. skin irritation, potential inhalation of vapours) and environment are also important factors in the selection process. It should be underlined that there is need to ensure appropriate contact between disinfection solution and contamination in proper time and temperature. Considering different properties of selected disinfectants and scenarios, there may be a need for additional action e.g. a pre-treatment shower (removing the organic substance, soaking which enhances contact), additional shower with neutral solution (removing the disinfectants) or application of PPE for protection against harmful activity of disinfecting substance. Thus, the knowledge about the components of the reagents used during work in the field and anticipated biological warfare agents may be helpful in selecting the adequate decontaminant which is simultaneously safe in use.

\section{References}

42 CFR Part 84 Approval of respiratory protective devices.

Cieslak T.J., Kortepeter M.G., Wojtyk R.J., Jansen H.J., Reyes R.A, Smith J.O. and NATO BioMedAC. Beyond the Dirty Dozen: A Matrix Methodology for Assessing Future Biowarfare Threats - NATO's Human Factors in Medicine (HFM-239) Symposium Vilnius, Lithuania, October 2014.

Council Directive 89/686/EEC of 21 December 1989 on the approximation of the laws of the Member States relating to personal protective equipment (for which only the national transpositions are legally binding).

Directive 2000/54/EC - biological agents at work of the European Parliament and of the Council of 18 September 2000 on the protection of workers from risks related 
to exposure to biological agents at work (seventh individual directive within the meaning of Article 16(1) of Directive 89/391/EEC).

EN 1073-2:2002 Protective clothing against radioactive contamination. Requirements and test methods for non-ventilated protective clothing against particulate radioactive contamination.

EN 12941:1998+A2:2008 Respiratory protective devices. Powered filtering devices incorporating a helmet or a hood. Requirements, testing, marking.

EN 12942:1998+A2:2008 Respiratory protective devices. Power assisted filtering devices incorporating full face masks, half masks or quarter masks. Requirements, testing, marking.

EN 13034:2005+A1:2009 Protective clothing against liquid chemicals. Performance requirements for chemical protective clothing offering limited protective performance against liquid chemicals (Type 6 and Type PB [6] equipment).

EN 133:2001 Respiratory protective devices - Classification.

EN 136:1998 Respiratory protective devices. Full face masks. Requirements, testing, marking.

EN 137:2006 Respiratory protective devices. Self-contained open-circuit compressed air breathing apparatus with full face mask. Requirements, testing, marking.

EN 140:1999 Respiratory protective devices. Half masks and quarter masks. Requirements, testing, marking.

EN 14126:2003 Protective clothing. Performance requirements and tests methods for protective clothing against infective agent.

EN 143:2000 Respiratory protective devices. Particle filters. Requirements, testing, marking.

EN 145:1998 Respiratory protective devices. Self-contained closed-circuit breathing apparatus compressed oxygen or compressed oxygen-nitrogen type. Requirements, testing, marking

EN 14605+A1:2009 Protective clothing against liquid chemicals - Performance requirements for clothing with liquid-tight (Type 3) or spray-tight (Type 4) connections, including items providing protection to parts of the body only (Types $\mathrm{PB}[3]$ and $\mathrm{PB}[4]$ ).

EN 149:2001+A1:2009 Respiratory protective devices. Filtering half masks to protect against particles. Requirements, testing, marking.

EN 943-1:2015 Protective clothing against dangerous solid, liquid and gaseous chemicals, including liquid and solid aerosols. Performance requirements for Type 1 (gastight) chemical protective suit.

EN 943-2:2002 Protective clothing against liquid and gaseous chemicals, aerosols and solid particles. Performance requirements for "gas-tight" (Type 1) chemical protective suits for emergency teams (ET).

EN ISO 13688:2013 Protective clothing. General requirements.

EN ISO 13982-1:2004+A1:2010 Protective clothing for use against solid particulates. Performance requirements for chemical protective clothing providing protection to the full body against airborne solid particulates (type 5 clothing).

EN ISO 17491-3:2008 Protective clothing. Test methods for clothing providing protection against chemicals. Determination of resistance to penetration by a jet of liquid (jet test). 
EN ISO 17491-4:2008+A1:2016 Protective clothing. Test methods for clothing providing protection against chemicals. Determination of resistance to penetration by a spray of liquid (spray test).

EN ISO 374-1:2016 Protective gloves against dangerous chemicals and micro-organisms. Terminology and performance requirements for chemical risk.

NATO - AEP-10 vol 1 NATO handbook for sampling and identification of biological and chemical agents - Vol. 1 procedures and techniques.

NATO handbook on the medical aspects of NBC defensive operation (biological) - AMedP-06 Vol. II; Ed. (C).

Ordinance of Council of Ministers concerning the list of occupational activities and recommended vaccination required among employees, officials, soldiers commencing work, employed or deputed to perform those activities (3 Jan 2012).

Ordinance of Minister of National Defence concerning vaccination programme for professional soldiers and the mode of registration of performed vaccination (3 Feb 2014).

Regulation (EU) 2016/425 of the European Parliament and of the Council of 9 March 2016 on personal protective equipment and repealing Council Directive 89/686/ EEC (Text with EEA relevance).

U.S. Department of Homeland Security (DHS) SAVER TechNote Self-Contained Breathing Apparatus, Full Facepiece, Closed Circuit, July 2014.

Waste Framework Directive of the European Union (2008/98/EC), Commission decision 2000/532/EC - of 3 May 2000 - on wastes classification.

www.emergency.cdc.gov.

www.phac-aspc.gc.ca/lab-bio/res/psds-ftss/index-eng.php. 